\title{
STABLE FUNCTIONS OF JANOWSKI TYPE
}

\section{Koneri Chandrasekran* , DeVASIRVATHAM John PrabHaKaran AND PRIYANKA SANGAL}

Abstract. A function $f \in \mathscr{A}_{1}$ is said to be stable with respect to $g \in \mathscr{A}_{1}$ if

$$
\frac{s_{n}(f(z))}{f(z)} \prec \frac{1}{g(z)}, \quad z \in \mathbb{D},
$$

holds for all $n \in \mathbb{N}$ where $\mathscr{A}_{1}$ denote the class of analytic functions $f$ in the unit disk $\mathbb{D}=\{z \in$ $\mathbb{C}:|z|<1\}$ normalized by $f(0)=1$. Here $s_{n}(f(z))$, the $n^{\text {th }}$ partial sum of $f(z)=\sum_{k=0}^{\infty} a_{k} z^{k}$ is given by $s_{n}(f(z))=\sum_{k=0}^{n} a_{k} z^{k}, n \in \mathbb{N} \cup\{0\}$. In this work, we consider the following function

$$
v_{\lambda}(A, B, z)=\left(\frac{1+A z}{1+B z}\right)^{\lambda}
$$

for $-1 \leqslant B<A \leqslant 1$ and $0 \leqslant \lambda \leqslant 1$ for our investigation. The main purpose of this paper is to prove that $v_{\lambda}(A, B, z)$ is stable with respect to $v_{\lambda}(0, B, z)=\frac{1}{(1+B z)^{\lambda}}$ for $0<\lambda \leqslant 1$ and $-1 \leqslant B<A \leqslant 0$. Further, we prove that $v_{\lambda}(A, B, z)$ is not stable with respect to itself, when $0<\lambda \leqslant 1$ and $-1 \leqslant B<A<0$.

Mathematics subject classification (2020): 30C45.

Keywords and phrases: Analytic functions, starlike functions, subordination and stable functions.

\section{REFERENCES}

[1] S. Chakraborty, A. Vasudevarao, On stable Functions, Comput. Methods Funct. Theory 18 (2018) 677-688.

[2] P. L. Duren, Univalent Functions, Springer-Verlag, Berlin, 1983.

[3] W. JANOWS KI, Some extremal problems for certain families of analytic functions, I, Ann. Polon. Math. 28 (1973), 297-326.

[4] S. R. Mondal and A. Swaminathan, Stable functions and extension of Vietoris' theorem, Results Math. 62 (2012), no. 1-2, 33-51.

[5] S. Ruscheweyh, Convolutions in geometric function theory, Séminaire de Mathématiques Supérieures, 83, Presses Univ. Montréal, Montreal, QC, 1982.

[6] S. RuscheweyH And L. Salinas, On starlike functions of order $\lambda \in[1 / 2,1)$, Ann. Univ. Mariae Curie-Skłodowska Sect. A 54 (2000), 117-123.

[7] S. Ruscheweyh and L. Salinas, Stable functions and Vietoris' theorem, J. Math. Anal. Appl. 291 (2004), no. 2, 596-604.

[8] S. Koumandos and S. Ruscheweyh, On a conjecture for trigonometric sums and starlike functions, J. Approx. Theory 149 (2007), no. 1, 42-58.

[9] P. Sangal And A. Swaminathan, On generalized Cesàro Stable functions, Mathematical Inequalities and Applications, 22 (1), (2019), 227-247.

[10] Wolfram Research, Inc. Mathematica. Version 10.0. 
[11] L. VIETORIS, Über das Vorzeichen gewisser trignometrishcher Summen, Sitzungsber, Oest. Akad. Wiss. 167, 1958, 125-135. 